\title{
Energy Absorption Due to Oblique Impact Crushing of Thin-Walled Tubes
}

\author{
Tsutomu Umeda $^{1, *}$ and Koji Mimura ${ }^{1}$ \\ ${ }^{1}$ Division of Mechanical Engineering, Graduate School of Engineering, Osaka Prefecture University, 1-1, Gakuen-cho, Naka-ku, Sakai, \\ Osaka 599-8531, Japan
}

\begin{abstract}
From the viewpoint of improving both the crash safety and the fuel efficiency, various shaped thinwalled tubes have been utilized as energy absorbers of automobiles such as front side members, crash boxes and so forth. In the axial crushing test of the regular polygonal tube, if the number of angles was small enough, it showed a certain inherent wrinkle mode, and the mean buckling load increased with that number, while it showed the mode of cylindrical tube if that number became larger. In the oblique crushing test, the same tendency was also shown within the range that the transition from axial collapse to bending collapse did not occur. This transition considerably decreases the mean buckling load so that it is important to know the threshold crush angle for the transition. Then, the crushing behavior of regular 4-12 angled tubes were investigated with changing the crush angle mainly by the experiment. The threshold angle is sensitively influenced by the initial imperfection and the boundary condition so that both the threshold angles obtained by the experiment and by the calculation for the square tube are $8-13^{\circ}$ smaller than that predicted by the equation proposed by Han and Park. For the carbon steel S25C, the increase of the strain rate in the axial collapse mode raises the mean buckling load, while it shows little strain rate dependence once the transition occurs.
\end{abstract}

\section{Introduction}

In recent years, improving the crash safety with keeping the fuel efficiency becomes more and more important for the carmaker, and the environmental issues and the progress in multi-material fabrication have also brought further requirements for the improvement. In the crash accident, a certain amount of the kinetic energy of automobiles will be dissipated as the plastic work in the axial or the lateral buckling of energy-absorbing components, most of which are thin-walled structures or tubes. From the practical viewpoint, most of those components are of various prismatic tubes so that the crushing behavior of rectangular tubes has been studied. Murase et al. studied the inextensional crushing mode of thin-walled square tube subjected to impulsive compressive load by means of the finite element method, in which the large deformation with material and geometric non-linearities was taken into consideration theoretically [1]. Wierzbicki and Abramowicz developed the mathematical model of thinwalled polygonal tubes on the basis of the rigid-perfectly plastic material approximation and the condition of kinematic continuity on the boundaries between rigid and deformable zones [2], and obtained a formula of the mean buckling load for the axially crushing square tube subjected to dynamic compressive load [3]. On the other hand, in general, the crash accident is not a full-lap collision but an offset collision so that the crushing behavior of prismatic tubes under oblique impact load have been also studied. Kecman carried out comprehensive experimental study on the bending collapse of rectangular tubes [4],

\footnotetext{
*e-mail: umeda@me.osakafu-u.ac.jp
}

and Wierzbicki also conducted analytical investigation on the bending deformation of rectangular tubes [5]. Furthermore, hat-type section columns [6], tapered square tubes [7] and aluminum foam-filled square tubes [8] subjected to oblique load have been also investigated. Han and Park studied the transition of the crushing behavior of rectangular tubes subjected to oblique dynamic load from axial collapse mode to bending collapse mode by means of the theoretical examination and the numerical simulation and obtained a certain equation, which estimates the threshold angle for that transition, from the approximation of theoretical and simulated data plotted [9].

In this study, to obtain the design policy of the energyabsorbing component subjected to offset collision, impact crushing tests of some regular polygonal tubes were carried out besides quasi-static and low-speed crushing tests with changing the crush angle from 0 to $30^{\circ}$. Then, the effects of the crush angle, the number of angles and the cross-head speed of testing device were discussed. The numerical simulation was also conducted to investigate the effects of crush angle and boundary condition using the explicit FEM code LS-DYNA [10].

\section{Experiment}

In order to grasp the material properties of specimen including the strain rate dependence, the tension tests within wide range of strain rates were conducted. Then, a series of axial and oblique crushing tests of regular polygonaltube specimens (the number of angles $n=4,5,6,10$, and 11) was performed. 


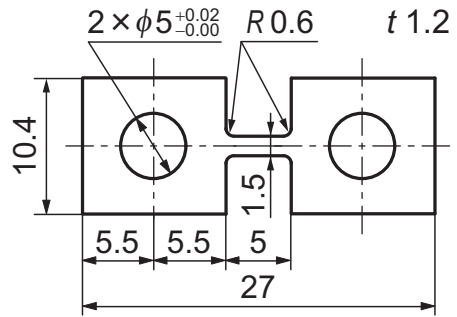

Fig. 1. Drawing of specimen for tension test.

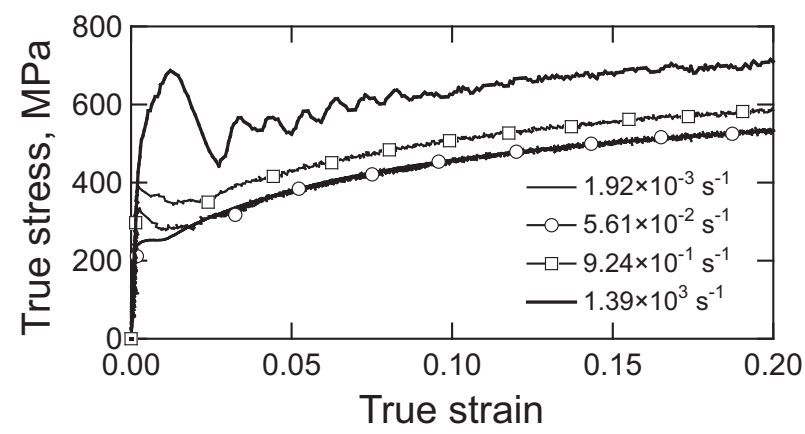

Fig. 2. Stress - strain relationships of normalized S25C at strain rates within the range from $10^{-3}$ to $10^{3} \mathrm{~s}^{-1}$.

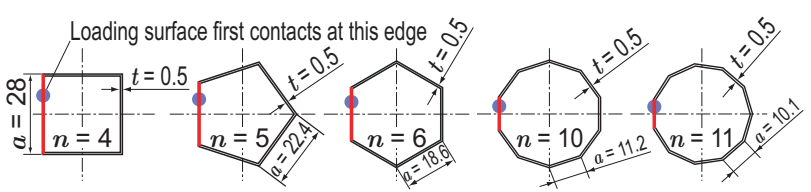

Fig. 3. Cross-sections of polygonal tube specimens $(L=100$ $\mathrm{mm})$.

\subsection{Specimens and the results of tension tests}

Regular polygonal tubes were quarried by the wire electric discharge machine from the block of carbon steel S25C for mechanical structure, which was normalized at 880$900{ }^{\circ} \mathrm{C}$ for 30 minutes per $25 \mathrm{~mm}$ thickness and was aircooled. The tension tests were carried out with the specimen shown in Figure 1, which was quarried from the block of normalized S25C, by means of AUTOGRAPH AGS-H $5 \mathrm{kN}$ (Shimadzu Corporation, the testing strain rate: $\sim 10^{-3}$ $\mathrm{s}^{-1}$ ), TS-2000 (Saginomiya Seisakusho, Inc., from $\sim 10^{-2}$ to $\sim 10^{0} \mathrm{~s}^{-1}$ ) and the non-coaxial Hopkinson bar method testing apparatus $\left(\sim 10^{3} \mathrm{~s}^{-1}\right)$. The true stress - true strain relationships within the strain-rate range from $10^{-3}$ to $10^{3}$ $\mathrm{s}^{-1}$ were obtained as shown in Figure 2 and shows remarkable strain rate dependence.

Figure 3 shows cross-sections of polygonal tube specimens used in the crushing test. The thickness $t$ is $0.5 \mathrm{~mm}$, the cross-sectional area $A$ is approximately $55 \mathrm{~mm}^{2}$, and the axial length $L$ is $100 \mathrm{~mm}$ while, for the oblique crushing test, that is extended $20 \mathrm{~mm}$ extra to fix the specimen on the testing device with the fixture of the same length. In the oblique crushing test, the load was applied to the leftside edge by the surface of loading part that was inclined from the horizontal plane. The circular tube of internal diameter $34.5 \mathrm{~mm}$ were also made with the same dimensions for $t, A$ and $L$.

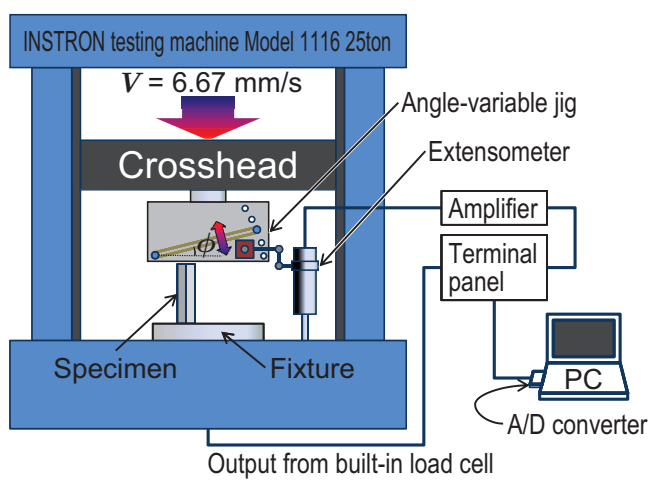

Fig. 4. Configuration of low-speed oblique crushing test.

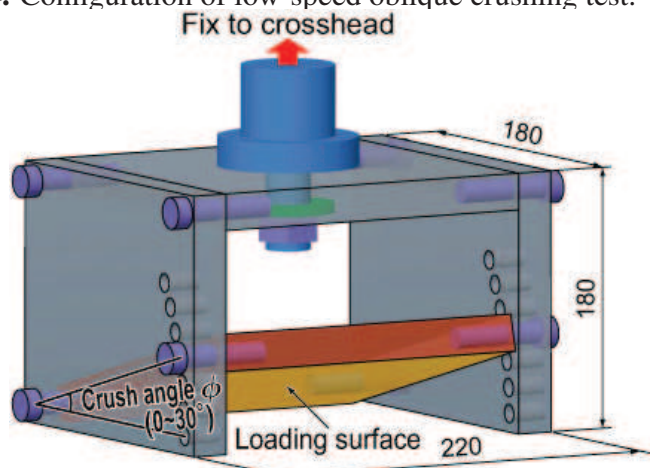

(a) Angle-variable jig

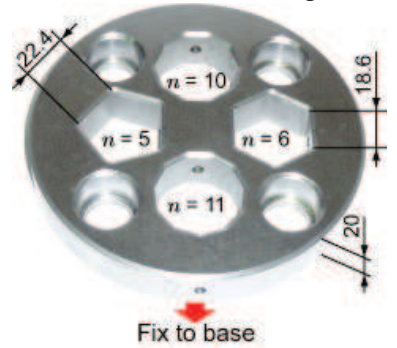

(b) Fixture

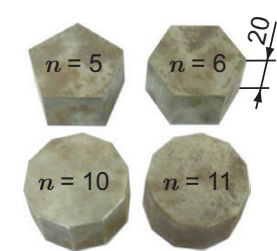

(b) Cores
Fig. 5. Jig, fixture and cores for Instron universal testing machine.

\subsection{Axial and oblique crushing tests}

To examine the effect of cross-head speed of testing machine, quasi-static and low-speed oblique crushing tests were also conducted by means of the Amsler-type hydraulic universal testing machine REH-30 (Shimadzu Corporation, the testing cross-head speed $V \cong 0.03 \mathrm{~mm} / \mathrm{s}$ ) and the Instron universal testing machine Model 1116 25ton $(V=6.67 \mathrm{~mm} / \mathrm{s})$ respectively. For example, Figure 4 shows the configuration of low-speed oblique crushing test. The angle-variable jig, fixture and cores in Figures 5 (a), (b) and (c) were used to apply the oblique load on the top of tubal specimen with fixing its bottom. The anglevariable jig is able to change the angle of loading surface from the horizontal plane, $\phi$, from 0 to $30^{\circ}$ by $5^{\circ}$, and the fixture and cores are $20 \mathrm{~mm}$ long in the axial direction so that those fit with the extra part of tubal specimen to fix that for lateral movement or rotation. The angle-variable jig and fixture were made of the rolled structural steel SS400. The cores were made of SS400 or the polyester resin while there was almost no difference due to the core material in the crushing behavior of specimen.

Figure 6 shows the configuration of impact oblique crushing test, and Figure 7 shows the photograph around the load sensing block with specimen $(n=5)$ and stopper. 


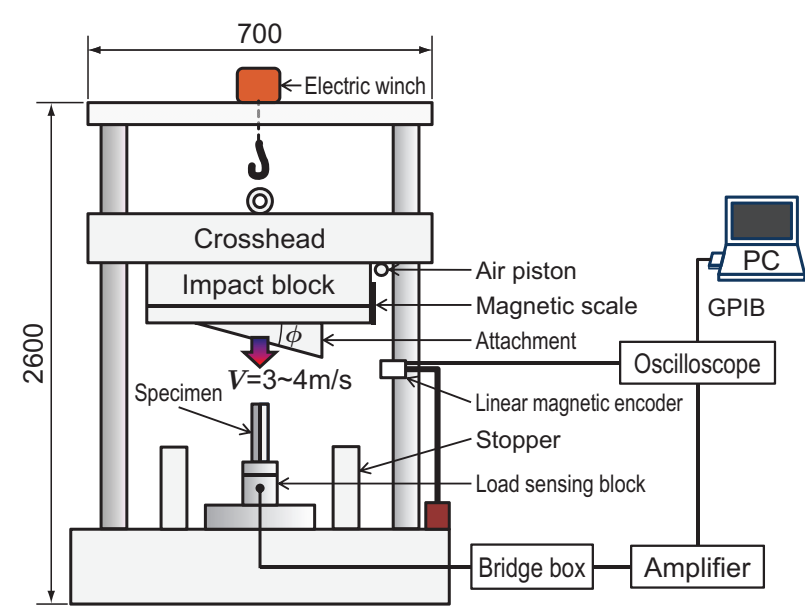

Fig. 6. Configuration of impact oblique crushing test.

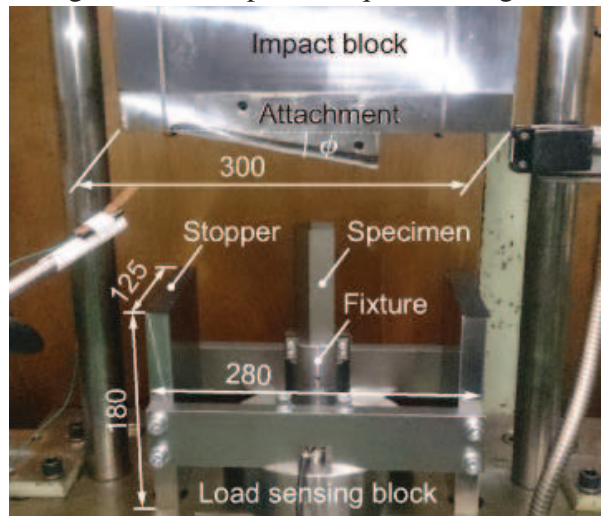

Fig. 7. Photograph around load sensing block with specimen $(n=5)$ and stopper.

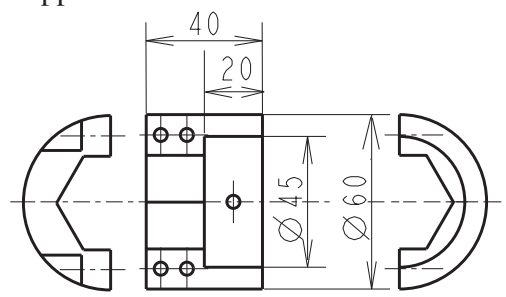

Fig. 8. Schematic drawing of the fixture of specimen $(n=6)$.

The drop-weight testing machine was used with the crosshead speed of 3-4 m/s at the impact moment. The oblique impact was applied to the top of specimen using the inclined surface of attachment $\left(\phi=0,10,15,20\right.$, and $\left.30^{\circ}\right)$ on the impact block $(38 \mathrm{~kg})$ and the extra part $(20 \mathrm{~mm})$ of specimen was fixed on the load sensing block with the core and the fixture shown in Figure 8. The impact block was prevented to move more than $80 \mathrm{~mm}$ using the stopper as shown in Figure 7. The attachment, fixture and stopper were made of the carbon steel S45C, and the induction hardening process were applied to the loading parts of attachment and load sensing block. The load and displacement were measured by the load sensing block and the linear magnetic encoder respectively.

Unless otherwise stated, the surfaces of loading part and specimen, which were contact with each other, were degreased using the acetone. The effective length of specimen is $100 \mathrm{~mm}$ so that the nominal strain rate becomes about $3 \times 10^{-4} \mathrm{~s}^{-1}$ for REH-30, $6.67 \times 10^{-2} \mathrm{~s}^{-1}$ for the In-

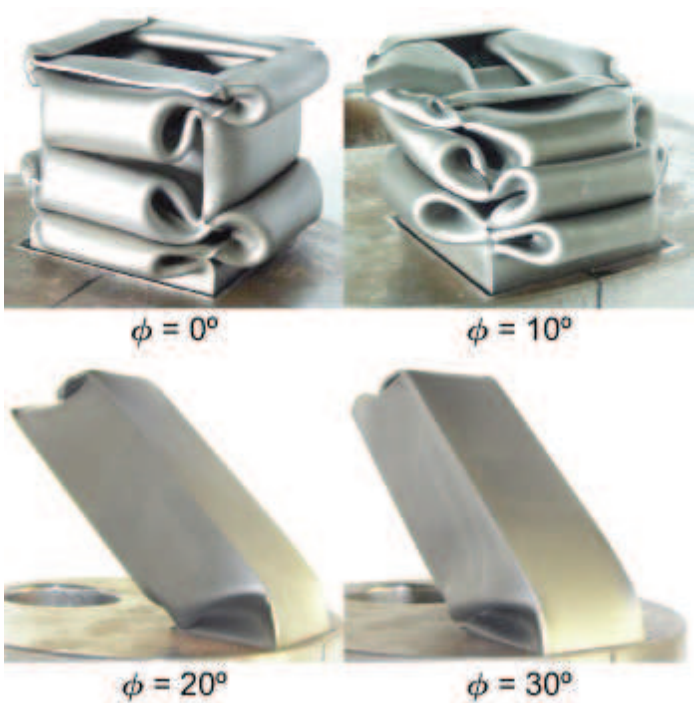

Fig. 9. Crushed square tubes $(n=4, V \cong 0.03 \mathrm{~mm} / \mathrm{s})$.

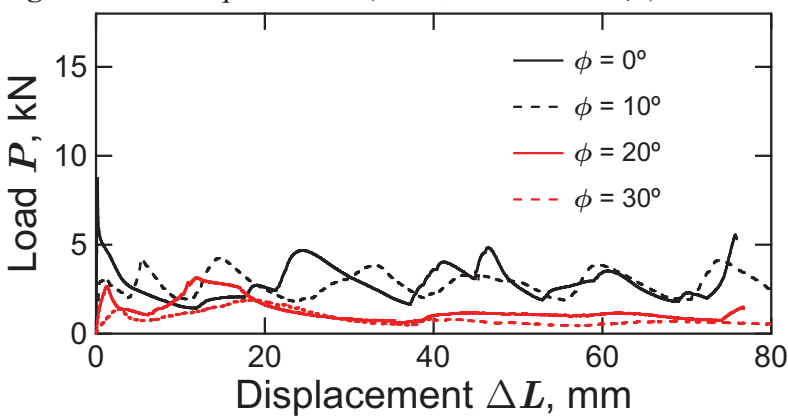

Fig. 10. $P-\Delta L$ relationships $(n=4, V \cong 0.03 \mathrm{~mm} / \mathrm{s})$.

stron testing machine and $3-4 \times 10^{1} \mathrm{~s}^{-1}$ for the drop-weight testing machine respectively. As shown in Figure 2, there is almost no difference of stress - strain relationship due to strain rate dependence between quasi-static $\left(3 \times 10^{-4} \mathrm{~s}^{-1}\right.$ for REH-30) and low-speed $\left(6.67 \times 10^{-2} \mathrm{~s}^{-1}\right.$ for the Instron testing machine) crushing tests.

\subsection{Examples of experimental results}

For example, Figure 9 shows crushed square tube specimens for $\phi=0,10,20$, and $30^{\circ}$ under the quasi-static crushing condition, and Figure 10 shows corresponding load $(P)$ - displacement $(\Delta L)$ relationships. The crushing behavior in Figure 9 shows the transition from axial collapse mode to bending collapse mode between $\phi=10^{\circ}$ and $20^{\circ}$, and the load level and absorbed energy also drop considerably within the same range of $\phi$.

In the same way, Figure 11 shows crushed hexagonal tube specimens for $\phi=0,10,20$, and $30^{\circ}$ under the lowspeed crushing condition. The transition of collapse mode also emerges between $10^{\circ}$ and $20^{\circ}$, though $V$ and $n$ are different from those for the quasi-static crushing tests of square tubes. Figure 12 shows corresponding $P-\Delta L$ relationships, and Figure 13 shows $P-\Delta L$ relationships of hendecagonal tube specimens under the same cross-head speed condition. It is found that the load level increases with $n$ if the axial collapse occurs while it is almost the same if the bending collapse occurs.

Figure 14 shows crushed pentagonal tube specimens for $\phi=0,10,15$, and $20^{\circ}$ under the impact crushing condition, and Figure 15 shows corresponding $P-\Delta L$ rela- 


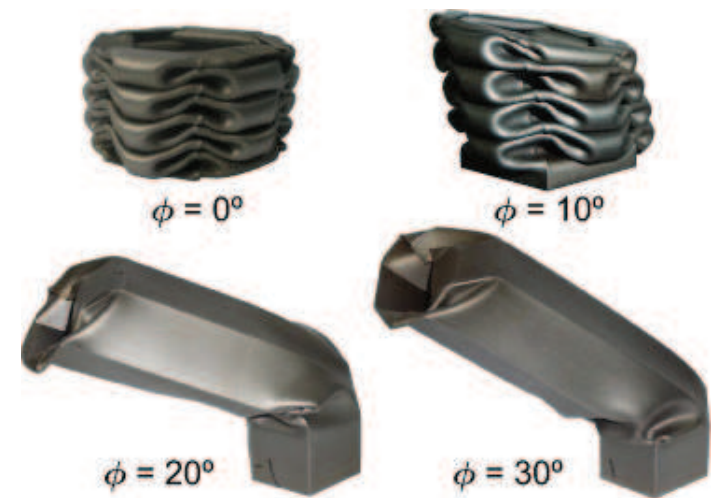

Fig. 11. Crushed hexagonal tubes $(n=6, V=6.67 \mathrm{~mm} / \mathrm{s})$.

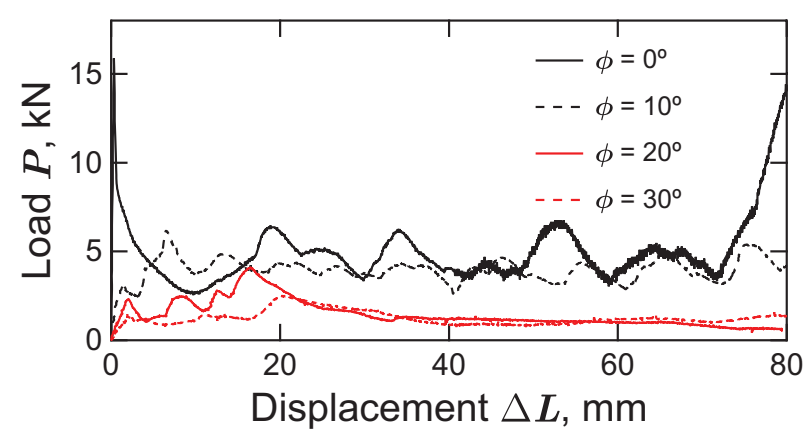

Fig. 12. $P-\Delta L$ relationships $(n=6, V=6.67 \mathrm{~mm} / \mathrm{s})$.

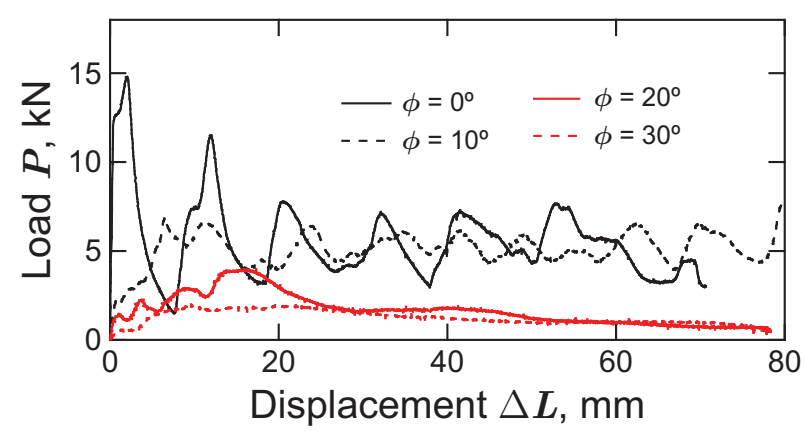

Fig. 13. $P-\Delta L$ relationships $(n=11, V=6.67 \mathrm{~mm} / \mathrm{s})$.

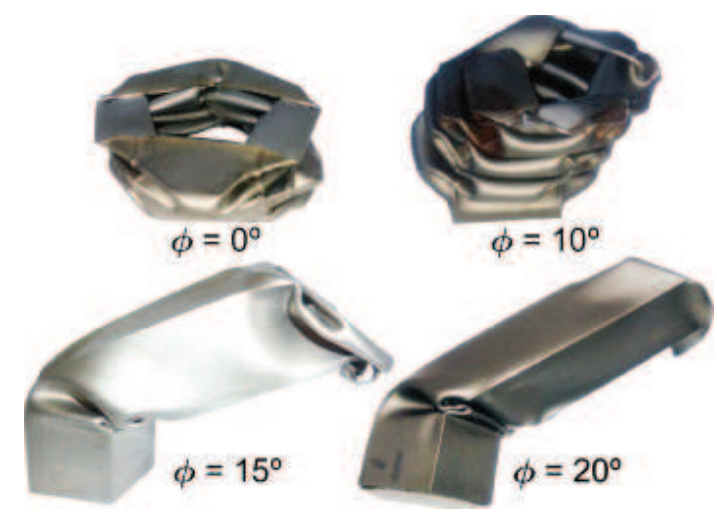

Fig. 14. Crushed pentagonal tubes $(n=5, V=3 \sim 4 \mathrm{~m} / \mathrm{s})$.

tionships. Though the higher harmonic oscillations are included, the load level increases due to the strain rate dependence as compared with those of $P-\Delta L$ relationships in Figures 10 and 11. The transition of collapse mode emerges between $10^{\circ}$ and $15^{\circ}$.

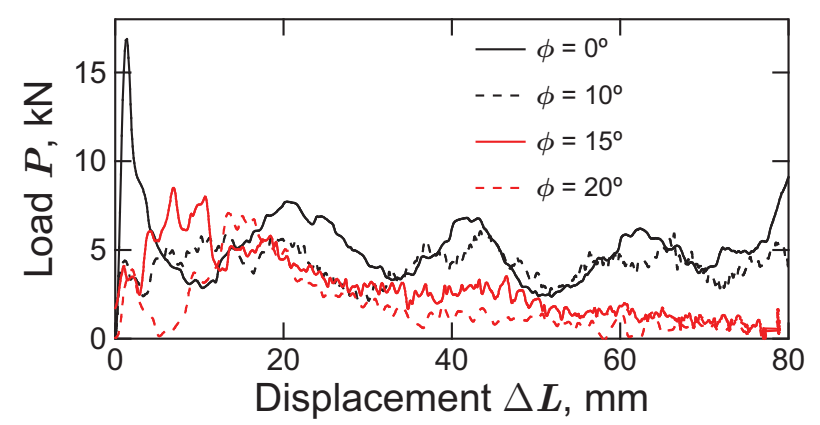

Fig. 15. $P-\Delta L$ relationships $(n=5, V=3-4 \mathrm{~m} / \mathrm{s})$.

\subsection{Numerical model}

Numerical simulations were performed using the explicit FEM code LS-DYNA Ver.971d [10] to mainly discuss the effects of $n$ and boundary condition. For example, Figure 16 shows the numerical model of hexagonal tube $(n=6)$ and its boundary condition. This model consists of 2700 quadrangular shell elements of BelytschkoLeviathan type (5 integration points in thickness direction) and 2754 nodes. The coefficient of friction, $\mu$, is given using the relative velocity between contact surfaces, $v_{\text {rel }}$, as follows:

$$
\mu=\mu_{k}+\left(\mu_{s}-\mu_{k}\right) e^{-\beta\left|v_{r e l}\right|}
$$

where $\mu_{s}$ and $\mu_{k}$ are the coefficients of static and kinetic friction respectively and $\beta$ is the exponential coefficient [10]. Here, it is assumed that $\mu_{s}=0.28, \mu_{k}=0.2$ and $\beta=0.001 \mathrm{~s} / \mathrm{mm}$. Furthermore, to reproduce natural buckling behavior, the pseudo-random number, the absolute value of which is less than $0.01 \mathrm{~mm}$, is taken by the linear congruential method and is added to the coordinates of nodes except those at the both ends, as initial imperfection.

The normalized S25C was modeled as an isotropic elastic-viscoplastic material, whose flow stress - plastic strain relationship was given by the Johnson-Cook model [11] as follows:

$$
\sigma_{y}=\left[\sigma_{0}+B\left(\bar{\varepsilon}^{p}\right)^{n_{J}}\right]\left(1+C \ln \frac{\dot{\bar{\varepsilon}}^{p}}{\dot{\varepsilon_{0}}}\right)
$$

where $\sigma_{y}, \bar{\varepsilon}^{p}$ and $\dot{\bar{\varepsilon}}^{p}$ are the flow stress, the equivalent plastic strain and its rate respectively. $\sigma_{0}, B$ and $n_{J}$ are the initial yield stress and the parameters related to workhardening at quasi-static strain rate respectively. $C$ and $\dot{\varepsilon}_{0}$ are the parameter related to strain rate dependence and the standard strain rate respectively. Table 1 shows respective material constants of the normalized S25C used in this study. The calculation of low-speed crushing tubes was carried out both by reducing $V$ within the limits of computing capability and by equating the effect of strain rate on the stress - strain relationship in the calculation with that under actual strain rate condition.

\subsection{Examples of calculated results}

Figure 17 shows the comparison of $P-\Delta L$ relationship under low-speed axial crushing condition among an experimental and two calculated results. Two calculated results were obtained under fixed-end and contact conditions at 
Table 1. Material constants of normalized S25C in Equation (2).

\begin{tabular}{ccccccc}
\hline $\begin{array}{c}\rho \\
{\left[\mathrm{kg} / \mathrm{m}^{3}\right]}\end{array}$ & $\begin{array}{c}E \\
{[\mathrm{GPa}]}\end{array}$ & $v$ & $\begin{array}{c}\sigma_{0} \\
{[\mathrm{MPa}]}\end{array}$ & $\begin{array}{c}B \\
{[\mathrm{MPa}]}\end{array}$ & $n_{J}$ & $C$ \\
\hline 7840 & 205 & 0.25 & 290 & 815 & 0.581 & 0.0265 \\
\hline
\end{tabular}

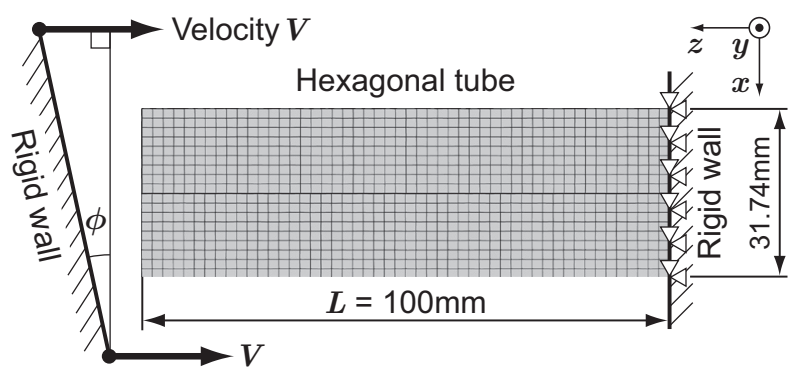

Fig. 16. Example of polygonal-tube model $(n=6)$.

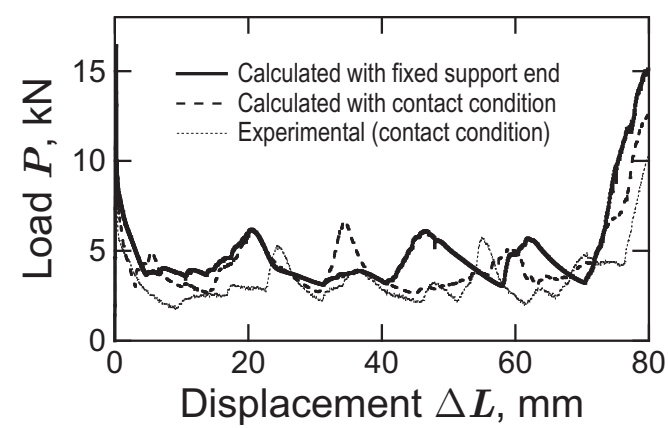

Fig. 17. Comparison of $P-\Delta L$ relationship under low-speed axial crushing condition between experimental and calculated re$\mathrm{su}^{\circ}$

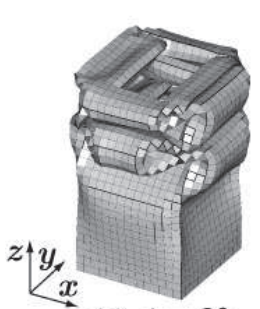

(a) $\phi=0^{\circ}$

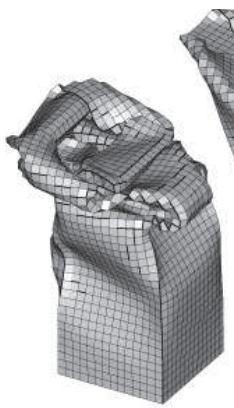

(b) $\phi=15^{\circ}$

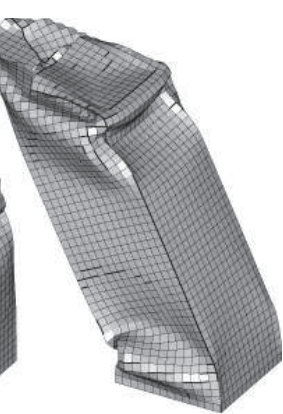

(c) $\phi=30^{\circ}$
Fig. 18. Deformation of square tubes calculated with changing $\phi$ under low-speed crushing condition $(n=4, \Delta L=50 \mathrm{~mm})$.

the supported end of tube respectively and show qualitative agreement with the experimental result. However, the load levels of the former results are higher than that of the latter. This difference might come from the accuracy of calculation using shell element for torsional deformation, friction and material models, the mesh dependence, the initial imperfection and so on. Figure 18 shows crushed square tubes at $\Delta L=50 \mathrm{~mm}$ for $\phi=0,15$ and $30^{\circ}$ under low-speed crushing condition, and Figure 19 shows calculated $P-\Delta L$ relationships of square tubes with changing $\phi$. The deformation of square tube for $\phi=30^{\circ}$ in Figure 18 (c) shows the bending deformation at the fixed end, and in Figure 19 the load level greatly decreases with changing $\phi$ from $20^{\circ}$ to $25^{\circ}$, so that the transition of collapse mode seems to occur between $20^{\circ}$ and $25^{\circ}$. However, the load level of each $P-\Delta L$ relationship in Figure 19 is rather larger than corresponding relationship in Figure 10.

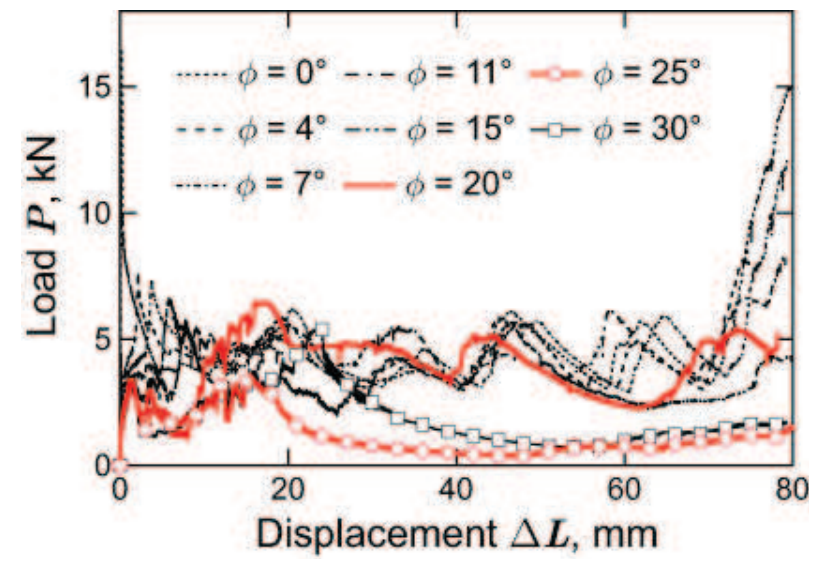

Fig. 19. Calculated $P-\Delta L$ relationships with changing $\phi(n=4)$.

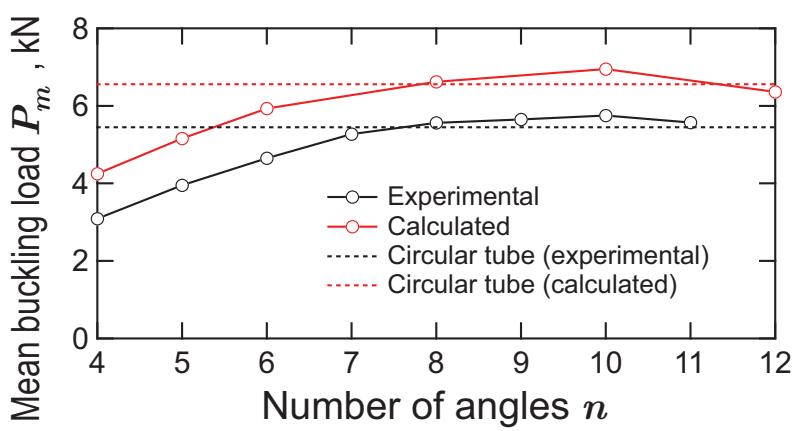

Fig. 20. Comparison of $P_{m}$ by low-speed axial crushing tests between experimental and calculated results.

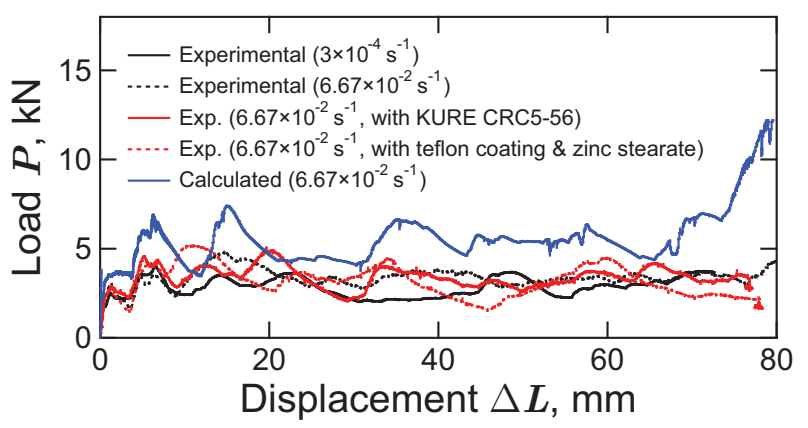

Fig. 21. Experimental and calculated $P-\Delta L$ relationships under different boundary conditions $\left(n=5, \phi=10^{\circ}\right)$.

\section{Effect of the number of angles and the boundary condition}

In this study, the energy absorption capacity is evaluated with the mean buckling load $P_{m}$, which is given by dividing the area under the curve of $P-\Delta L$ relationship up to $\Delta L=70 \mathrm{~mm}$ (before starting densification) by the same value of $\Delta L$. Figure 20 shows the comparison of $P_{m}-n$ relationship obtained under low-speed axial crushing condition between the experimental and calculated results. In both the results, first, $P_{m}$ increases with $n$ and has a peak value at $n=10$, then, it decreases a little so as to approach to the value of circular tube while each calculated value is about $1.2 \mathrm{kN}$ larger than corresponding experimental value. Figure 21 shows the comparison of $P$ $-\Delta L$ relationship of pentagonal tube for $\phi=10^{\circ}$ among 


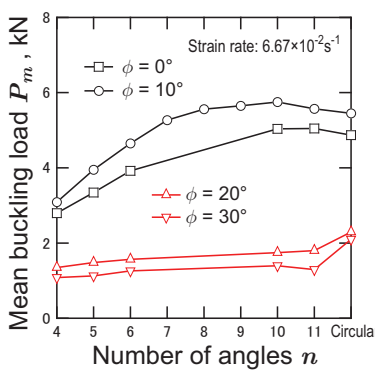

(a) Low-speed

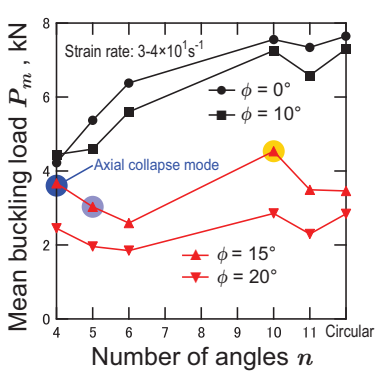

(b) Impact
Fig. 22. Variation of $P_{m}$ with $n$ (experimental results).

the results for different boundary conditions and the calculated result. Here, to discuss the difference between experimental and calculated results, oblique crushing tests were performed under four conditions; 1) quasi-static, 2) lowspeed, 3) low-speed and lubricated with KURE CRC556 and 4) low-speed and lubricated with teflon coating and zinc stearate. Surely, the experimental results under those conditions are different from each other, and especially the difference between quasi-static and low-speed crushing tests implies the velocity dependence of the coefficients of friction because this material has no strain rate dependence within the range from quasi-static to lowspeed conditions. The calculated result was obtained under the low-speed crushing condition, and its load level is still larger than that of any experimental result. Changing the magnitude of the coefficient of friction and the initial imperfection, the adoption of another material model, and the refinement of mesh size have been also investigated to some extent, however, those were not so effective so far. In this study, therefore, the numerical analysis is confined to qualitative evaluation.

\section{Effect of crush angle}

Han and Park proposed the equation that predicts the threshold angle of transition for square tube [9] as follows:

$$
\phi_{c}=4.81+1564.00 e^{-1.12(L / a)}
$$

where $\phi_{c}$ and $a$ are the threshold angle and the width of square tube respectively. In this study, $a=28 \mathrm{~mm}, L=$ $100 \mathrm{~mm}$ so that $\phi_{c}=33.5^{\circ}$. This value is $8-13^{\circ}$ larger than the crush angle $\phi$, at which the bending collapse mode was confirmed by the experiment $\left(20^{\circ}\right)$ and the numerical analysis $\left(25^{\circ}\right)$. Figure 22 (a) and (b) show the variation of the mean buckling load $P_{m}$ with the crush angle $\phi$ and the number of angles $n$ under the low-speed and the impact crushing conditions respectively. Under the lowspeed crushing condition, the transition of collapse mode occurs between $\phi=10^{\circ}$ and $20^{\circ}$ for all $n$, and $P_{m}$ greatly decreases and becomes almost constant regardless of $n$ in the bending collapse mode. Under the impact crushing condition, $P_{m}$ grows with the strain rate. For $\phi=15^{\circ}$, the square tube caused the axial collapse mode in a probability of two in three, and the pentagonal tube also caused the axial collapse mode in a probability of one in three. The polygonal tubes of $n \geq 6$ caused the bending collapse mode. Then, the transition of collapse mode occurs around $\phi=15^{\circ}$, and it is expected that $\phi_{c}$ decreases with the increase of $n$. Furthermore, $P_{m}$ increases even in the bending collapse mode to a certain extent, and particularly $P_{m}$ has a peak value for $n=10$.

\section{Conclusions}

In order to obtain the design policy of the energy absorbing component subjected to oblique load, impact crushing tests of some regular polygonal tubes were performed besides quasi-static and low-speed crushing tests with changing the crush angle $\phi$. The transition of collapse mode occurs between $\phi=10^{\circ}$ and $20^{\circ}$ in the experiment and between $20^{\circ}$ and $25^{\circ}$ in the numerical simulation for the polygonal tubes used in this study. In the axial collapse mode, the mean buckling load increases with the number of angles, $n$, and has a peak value at $n=10$, then it decreases a little to approach to the value of circular tube. It also increases with the strain rate if the material has the strain rate dependence. In the bending collapse mode, the mean buckling load is not so sensitive to $n$ and shows little strain rate dependence. The results of impact crushing tests show that the threshold value, $\phi_{c}$, is around $15^{\circ}$ and $\phi_{c}$ decreases with the increase of $n$.

\section{References}

1. Murase, K., Katori, H. and Nishimura, T., Bull. Japan Soc. Mech. Eng. 26, 923-929 (1983)

2. Wierzbicki, T. and Abramowicz, W., Journal of Applied Mechanics 50, 727-734 (1983)

3. Abramowicz, W. and Jones, N., Int. J. Impact Engng. 2-2, 179-208 (1984)

4. Kecman, D., International Journal of Mechanical Sciences, 25-9\&10, 623-636 (1983)

5. Wierzbicki, T., Recke, L., Abramowicz, W., Gholami, T., and Huang, J., Computers \& Structures, 51-6, 611623 (1994)

6. Wallentowitz, H. and Adam, H., design materials and innovative joining methods. Int. J. Crashworthiness, 1-2, 163-180 (1996)

7. Reid, S.R. and Reddy, T.Y., International Journal of Mechanical Sciences, 2-9, 623-637 (1986) International Journal of Impact Engineering, 32, 1595-1620 (2006)

8. Reyes, A., Hopperstad, O.S. and Langseth, M., International Journal of Solids and Structures 41, 1645-1675 (2004)

9. Han, D.C. and Park, S.H., Thin-Walled Structures 35, 167-184 (1999) Proceedings of the 58th Japan Congress on Materials Research (in Japanese) (The Society of Materials Science, Japan, 2014), 64-65

10. Livermore Software Technology Corp. (Ed.) and JSOL Corporation (Tr.), LS-DYNA Ver.971 User's Manual, I\&II (in Japanese) (JSOL Corporation, Japan, 2007)

11. Johnson, G.R. and Cook, W.H., Proceedings of the 7th International Symposium on Ballistics (The Hague, The Netherlands, 1983), 541-547 